BACKGROUND: The proinflammatory chemokine CXCL10, in addition to its chemotactic properties, is also involved in the stimulation of natural killer and T-cell migration in Mycobacterium tuberculosis infection. In this study, our experiments were designed to determine the role of interferon (IFN)- $\alpha \beta$ in the production of CXCL10 by human monocytes infected with Mycobacterium bovis bacillus Calmette-Guérin (BCG).

Methods: The concentrations of CXCL10 in culture supernatants of monocytes infected with $M$. bovis $B C G$ were determined by enzyme-linked immunosorbent assay. CXCL10 mRNA levels were determined by the reverse transcription-polymerase chain reaction method.

Results: We have shown the induction of CXCL10 following infection with $M$. bovis BCG in a dosedependent and time-dependent manner. Importantly, the secretion of CXCL10 in response to M. bovis was increased by IFN- $\alpha$. These results were further confirmed by the fact that the addition of an anti-IFN- $\alpha \beta$ neutralizing antibody completely reversed the stimulatory effect, whereas an isotype-matched control antibody had no significant effect on CXCL10 secretion. It is important to note that no significant effect of type I IFN on CXCL8 production in M. bovisinfected monocytes was observed. This was consistent with the finding by the reverse transcriptionpolymerase chain reaction method that treatment with anti-IFN- $\alpha / \beta$ antibodies potentially inhibited CXCL10 mRNA levels, whereas no significant effect was observed on CXCL8 mRNA. Moreover, in THP-1 monocytes and THP-1 macrophages, the addition of exogenous IFN- $\alpha$ stimulated CXCL10 secretion.

Conclusions: Collectively, these results indicate that the type I IFN may play an important role to modulate the expression of CXCL10 in M. bovis BCG infection. Studies on $M$. bovis-induced chemokine secretion could provide important insight into the regulation of the immune response against tuberculosis.

Key words: Bacillus Calmette-Guérin, CXC chemokine ligand 10, Interferon $\alpha \beta$, Mycobacterium bovis

\section{Role of type I interferon in the bacillus Calmette-Guérin-induced expression of CXCL10 from human monocytes}

\author{
Patricia Méndez Samperio ${ }^{\mathrm{CA}}$, Artemisa Trejo and \\ Elena Miranda
}

Departamento de Inmunología, Escuela Nacional de Ciencias Biológicas, IPN, Carpio y Plan de Ayala, México, D.F. 11340 México

\author{
${ }^{\mathrm{CA}}$ Corresponding Author \\ Tel: +57296000 , ext. 62499 \\ Fax: +53963503 \\ E-mail: pmendezs@bios.encb.ipn.mx
}

\section{Introduction}

The proinflammatory response of infected human monocytes is an important early host defense mechanism against mycobacterial infection. Recently, it has been estimated that one-third of the world's population is infected with Mycobacterium tuberculosis. ${ }^{1}$ Mycobacterium bovis bacillus CalmetteGuérin (BCG) is currently administered as the only available vaccine for the prevention of tuberculosis in humans. ${ }^{2}$ Protective immunity against tuberculosis requires productive infection of the host by $M$. bovis BCG. Infection of human cells with $M$. bovis induces release of various chemoattractants. Chemokines are recently identified chemotactic cytokines and can be divided into four subfamilies according to the $\mathrm{N}$ terminal cysteine positioning in their amino acid sequence: $\mathrm{CXC}, \mathrm{CC}, \mathrm{CX}_{3} \mathrm{C}$, and $\mathrm{C}^{3}$ Chemokines induce changes in target cell membrane protein composition, thus enhancing chemotaxis of leukocytes through the vascular endothelium into the inflamed tissues. It has been reported that CCL3, CCL4, CCL5, and CXCL8 are released by human alveolar macrophages upon infection with $M$. tuberculosis. ${ }^{4}$ We recently reported that human monocytes infected with $M$. bovis stimulate the secretion of CXCL8. ${ }^{5,6}$ Increased chemokine secretion has been observed in monocytes and polymorphonuclear granulocytes after infection with $M$. tuberculosis. ${ }^{7-9}$ Moreover, it has been shown that M. tuberculosis- 
induced chemokine production from macrophages is regulated by different factors, such as host cell surface molecules, ${ }^{10}$ and mycobacterial cell wall components. $^{11}$

It has also been demonstrated that interferon (IFN) may induce the expression of certain chemokines genes, such as those of CXCL9, CXCL10, and CXCL11. ${ }^{12,13}$ IFN have been divided into two classes (type I and type II) on the basis of their structure, function, and cellular origin. Both types are involve in different mechanisms of innate and adaptive immunity. ${ }^{14-16}$ The IFN- $\alpha / \beta$ system helps host defense against $M$. tuberculosis in mice. ${ }^{17}$ Recent studies have highlighted the production of type I IFN following $M$. tuberculosis infection. ${ }^{18,19}$ However, it is not known whether the expression of chemokines during infection of human monocytes with $M$. bovis is dependent on type I IFN. In this study, we have investigated the secretion of CXCL10 during infection of human monocytes with $M$. bovis. Furthermore, we evaluated the effect of IFN $-\alpha / \beta$ on the production of chemokines from $M$. bovis-infected human monocytes.

\section{Materials and methods}

\section{Reagents}

Recombinant IFN- $\alpha$ and control antibody isotype were purchased from Sigma-Aldrich (St Louis, MO, USA). Rabbit polyclonal antiserum raised against IFN$\alpha$ and IFN- $\beta$ were obtained from PBL Biomedical Laboratories (New Brunswick, NJ, USA), Live $M$. bovis BCG, Danish Strain 1331 was kindly supplied by Dr J. Ruiz-Puente (Birmex, México). BCG was grown at $37^{\circ} \mathrm{C}$ in Sauton medium using stationary tissue culture flasks. Mycobacterial viability, as assessed by the number of colony-forming units, was $60-70 \%$.

\section{Cell culture}

Peripheral blood mononuclear cells were isolated from healthy donors by density centrifugation over Ficoll-Hypaque gradient (Histopaque; Sigma) $(d=$ 1.007). Human monocytes were purified by positive selection with magnetic microbead-coated antibody (Miltenyi Biotec, Gladbach, Germany). Cells were incubated with beads conjugated to monoclonal mouse anti-human CD14 antibody (Leu-3a). The recovered primary cells were $>96 \% \mathrm{CD} 14^{+}$cells as determined by flow cytometry with anti-CD14 antibody. Viability, as determined by trypan blue exclusion test, was $>97 \%$. THP-1 cells were obtained from the American Type Culture Collection. Cells were then cultured in fresh RPMI 1640 medium supplemented with $2 \mathrm{mM}$ l-glutamine, $100 \mathrm{U} / \mathrm{ml}$ of peni- cillin, $100 \mu \mathrm{g} / \mathrm{ml}$ of streptomycin, and 10\% fetal calf serum in a $5 \% \mathrm{CO}_{2}$ incubator at $37^{\circ} \mathrm{C}$. THP-1 cells were maintained in logarithmic growth (between $2 \times$ $10^{5}$ cells $/ \mathrm{ml}$ and $10^{6}$ cells $/ \mathrm{ml}$ ) by passage every 3-4 days. Infection of cells with $M$. bovis was performed at a multiplicity of infection (MOI) of 5, unless otherwise stated.

Uninfected cells were cultured and harvested in parallel, and used as controls. In certain experiments, cultured cells were incubated with $M$. bovis alone or in the presence of increasing concentrations of exogenous IFN- $\alpha$. Neutralizing antibody IFN- $\alpha / \beta$ was added at different concentrations to some cultures.

\section{Chemokine detection}

The culture supernatants from control and M. bovisinfected cell cultures were harvested at different times after infection, centrifuged to remove any debris, were filtered (0.2- $\mu \mathrm{m}$ filters), and were stored at $-20^{\circ} \mathrm{C}$ until use. Levels of CXCL8, and CXCL10 in each of the supernatants were determined using the kit human CXCL8 or CXCL10 enzyme-linked immunosorbent assay (ELISA) system (R\&D System, Minneapolis, MN, USA). The ELISA assays were carried out according to the manufacturer's instructions.

Optical density readings were obtained with a microplate reader (model Labsystems Multiskan MS, Finland).

\section{Reverse transcription-polymerase chain reaction}

mRNA expression of CXCL10 and CXCL8 in M. bovisinfected monocytes was analyzed by the reverse transcription (RT)-polymerase chain reaction (PCR) method. Cells were treated with anti-IFN- $\alpha \beta(10 \mu \mathrm{g} /$ $\mathrm{ml}$ ), and were then infected with $M$. bovis at MOI $=5$. Total RNA from cells was isolated by the method of Chomczynski and Sacchi. ${ }^{20}$ Briefly, total RNA was extracted with TRIzol (Life Technologies, Rockville, MD) for $5 \mathrm{~min}$ at room temperature, transferred to a microcentrifuge tube, and then $200 \mu$ of cloroform was added, vortex mixed, and incubated for $10 \mathrm{~min}$. After centrifugation for $5 \mathrm{~min}$, the aqueous layer was transferred to a fresh tube, and RNA was precipitated by adding an equal volume of isopropanol. After centrifugation, the RNA pellet was dried and dissolved in $50 \mu$ of sterile water. The RNA concentration was determined by optical density measurements. One microgram of RNA was reversibly transcribed using random hexamer primers (GIBCO BRL, Rockville, MD) and Superscript II reverse transcriptase (GIBCO BRL). The resulting cDNA was subjected to PCR, for a total of 20 cycles in the standard reaction mixture using Taq DNA polymerase and the appropriate CCXL8 or CXCL10 primers (Clontech Laboratories, Palo Alto, CA, USA). 
An aliquot of the amplified product was run on a $2 \%$ agarose gel in TBE. After electrophoresis, the gel was stained for $5 \mathrm{~min}$ in ethidium bromide (1\%) and photographed. PCR primers for GAPDH were used as an internal control.

\section{Statistical method}

Data are expressed as the mean \pm standard error of the mean of at least three independent experiments using cells from different individuals. Comparisons between groups were made by analysis of variance. Comparisons between two groups were performed using Student's $t$ test. $p<0.01$ was considered statistically significant.

\section{Results}

\section{Production of CXCL10 by human monocytes infected with $M$. bovis BCG}

In the first set of experiments, we examined the CXCL10 secretion of human monocytes following stimulation with $M$. bovis at $\mathrm{MOI}=5, \mathrm{MOI}=3$, $\mathrm{MOI}=1$, or $\mathrm{MOI}=0.1$. As indicated in Fig. $1 \mathrm{~A}$, CXCL10 production was clearly detected in a dosedependent manner after infection with $M$. bovis and a maximal secretion was reached with $\mathrm{MOI}=5$ of $M$. bovis. No CXCL10 secretion was observed in the absence of stimulation. There was no further significant increase of CXCL10 secretion at higher doses of $M$. bovis (data not shown). Next, we analyzed the kinetic of CXCL10 secretion in human monocytes during $M$. bovis infection. Human monocytes were infected with $M$. bovis at $\mathrm{MOI}=5$ and cell culture supernatants were collected at different time points after infection to determine the concentration of CXCL10 by ELISA. As shown in Fig. 1B, human monocytes infected with $M$. bovis showed that CXCL10 production was in a time-dependent manner.

\section{Effect of type I IFN on CXCL10 production in $M$. bovis-infected human monocytes}

Because IFN- $\alpha \beta$ has been shown to be able to induce the expression of certain chemokine genes, ${ }^{12,13}$ we next sought to determine whether exogenous IFN- $\alpha$ regulates the CXCL10 secretion in $M$. bovis-infected human monocytes. Human monocytes were infected with $M$. bovis at MOI $=5$ and treated with increasing concentrations of IFN- $\alpha$. As shown in Fig. 2A, the production of CXCL10 in response to $M$. bovis was increased by IFN- $\alpha$. This amount was significant $(p<0.01)$. To further evaluate the specificity of the effect of IFN- $\alpha$ on $M$. bovis-induced CXCL10 production, a neutralizing antibody to IFN- $\alpha \beta(10 \mu \mathrm{g} / \mathrm{ml})$
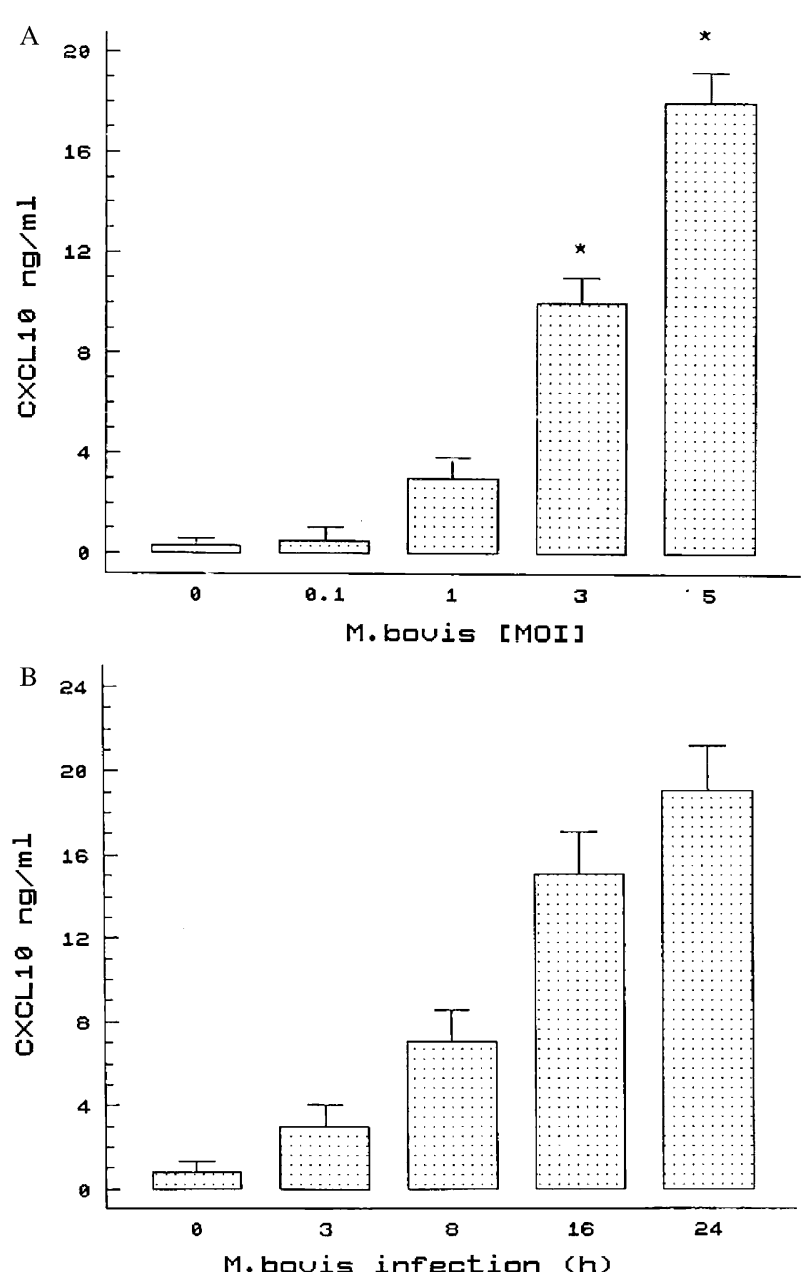

FIG. 1. (A) Dose-dependent and (B) time-dependent expression of CXCL10 by human monocytes infected with $M$. bovis. The dose-dependent effect was studied using human monocytes $\left(10^{6} /\right.$ well) cultured in medium alone or infected with M. bovis at $\mathrm{MOI}=5, \mathrm{MOI}=3, \mathrm{MOI}=1$, or $\mathrm{MOI}=0.1$. $\mathrm{CXCL} 10$ secretion was measured by ELISA $24 \mathrm{~h}$ after infection. ${ }^{*} p<0.01$ compared with the value obtained with medium alone. The time-dependent effect was evaluated using human monocytes infected with $M$. bovis at $\mathrm{MOI}=5$ and cell culture supernatants were collected at different time points after infection and analyzed for CXCL10 secretion by ELISA. The results are means \pm standard errors of the means for four independent experiments.

or an isotype-matched control antibody $(10 \mu \mathrm{g} / \mathrm{ml})$ was added to $M$. bovis-infected monocytes and treated with IFN- $\alpha(1000 \mathrm{U} / \mathrm{ml})$ for $24 \mathrm{~h}$ at $37^{\circ} \mathrm{C}$. As indicated in Fig. 2B, stimulation of $M$. bovis-mediated CXCL10 secretion by IFN- $\alpha$ (67\% increment) was completely neutralized with $10 \mu \mathrm{g}$ of anti-IFN$\alpha \beta$ antibody/ml. In contrast, an isotype-matched control immunoglobulin $G_{1}$ antibody was without effect (Fig. 2B).

In order to determine whether the effect of type I IFN would also be observed on other chemokines secreted in $M$. bovis-infected human monocytes, we analyzed the production of CXCL8 in the supernatants of $M$. bovis-infected human monocytes in the presence or absence of increasing concentrations of 

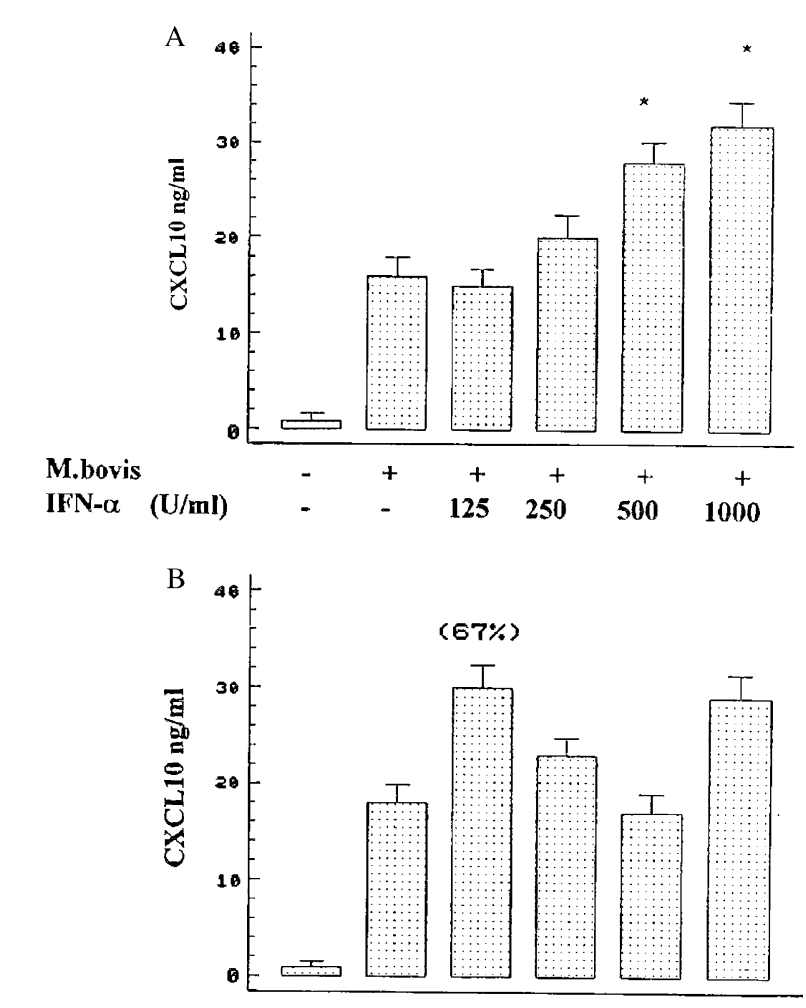

$\begin{array}{lcccccc}\text { M.bovis } & - & + & + & + & + & + \\ \text { IFN- } \alpha(1000 \mathrm{U} / \mathrm{ml}) & - & - & + & + & + & + \\ \text { Anti-IFN- } \alpha \beta(\mu \mathrm{g} / \mathrm{ml}) & - & - & - & 2 & 10 & - \\ \text { Isotype control Ab }(\mu \mathrm{g} / \mathrm{ml}) & - & - & - & - & - & 10\end{array}$

FIG. 2. Effects of exogenous type I IFN on CXCL10 production in $M$. bovis-infected human monocytes. (A) Human monocytes $\left(10^{6} /\right.$ well) were cultured in medium alone or infected with $M$. bovis at $\mathrm{MOI}=5$, and were treated with increasing concentrations of exogenous IFN- $\alpha$ for $24 \mathrm{~h}$ at $37^{\circ} \mathrm{C}$. Cell culture supernatants were harvested and CXCL10 protein was measured by ELISA. ${ }^{*} p<0.01$ compared with the value obtained with medium alone. (B) Human monocytes were treated with exogenous IFN- $\alpha(1000 \mathrm{U} / \mathrm{ml})$ in the presence or absence of a neutralizing antibody to IFN- $\alpha \beta$ or an isotypematched control antibody. Cell culture supernatants were collected $24 \mathrm{~h}$ after $M$. bovis infection and analyzed with CXCL10-specific ELISAs. The results represent the means + standard errors of the means of five separate experiments. The number in parentheses indicates the percentage of increment by IFN- $\alpha$ with respect to $M$. bovis cultures. + , present; -, absent.

exogenous IFN- $\alpha$. As shown in Fig. 3, no significant effect was detected in this other chemokine.

We next sought to analyze the effect of IFN- $\alpha \beta$ system on monocytes and macrophages, since both cell types are exposed to infection by mycobacteria in vivo. We analyzed the effect of IFN- $\alpha$ on M. bovisinduced secretion of CXCL10 using the THP-1 cell line, which has long been used to study phorbol ester-induced monocyte-to-macrophage differentiation. ${ }^{21}$ THP-1 macrophages (phorbol ester-treated) and THP-1 monocytes (untreated) were infected with $M$. bovis at $\mathrm{MOI}=5$ in the presence or absence of IFN- $\alpha$. In accordance with primary cell experiments, the addition of $1000 \mathrm{U} / \mathrm{ml}$ of IFN- $\alpha$ to THP-1 macrophages and THP-1 monocytes increased CXCL10 secretion in M. bovis-infected cells (Fig. 4).

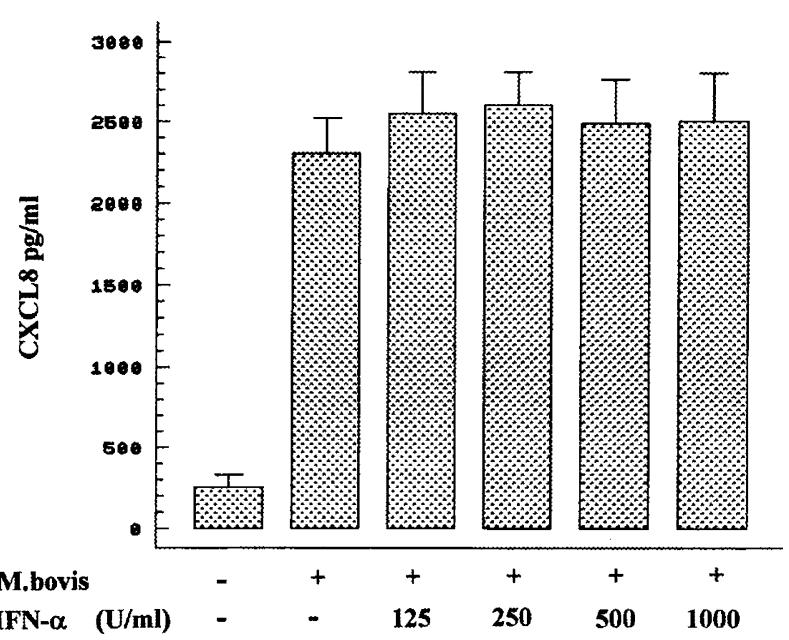

FIG. 3. Effect of recombinant IFN- $\alpha$ on $M$. bovis-mediated CXCL8 secretion. Human monocytes were cultured in medium alone or infected with $M$. bovis at $\mathrm{MOI}=5$, and treated with increasing concentrations of exogenous IFN- $\alpha$. Cell culture supernatants were harvested after $24 \mathrm{~h}$ and CXCL8 protein was measured by ELISA. Results of ELISAs are expressed as $\mathrm{pg} / 10^{5}$ cells, and are means \pm standard errors of the means for six independent experiments.

It is important to note that the effect of IFN- $\alpha$ was more significant in THP-1 macrophages.

\section{IFN- $\alpha \beta$ effect on CXCL10 mRNA expression}

To further study the effect of type I IFN in CXCL10 gene expression, total cellular RNA was isolated from $M$. bovis-infected human monocytes and treated with $10 \mu \mathrm{g} / \mathrm{ml}$ of a neutralizing anti-IFN- $\alpha \beta$ antibody. The

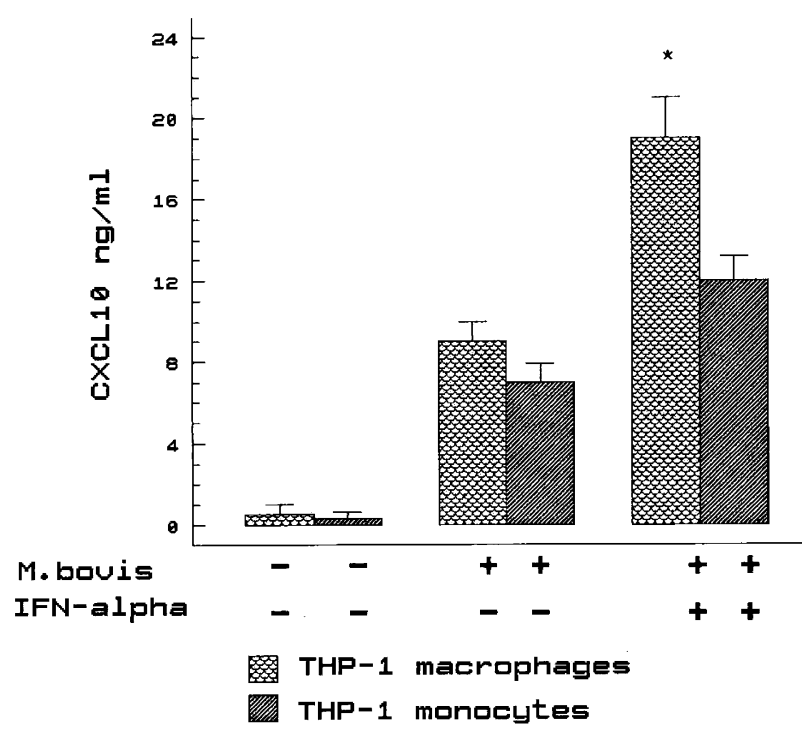

FIG. 4. Effect of the IFN- $\alpha \beta$ system on $M$. bovis-induced secretion of CXCL10 using the THP-1 cell line. THP-1 macrophages and THP-1 monocytes were infected with $M$. bovis at $\mathrm{MOI}=5$ in the presence or absence of $1000 \mathrm{U} / \mathrm{ml}$ of exogenous IFN- $\alpha$. Cell culture supernatants were harvested and CXCL10 protein was measured by ELISA. The results are means \pm standard errors of the means for six independent experiments. ${ }^{*} p<0.01$ compared with the value obtained with $M$. bovis alone. +, present; -, absent. 
A

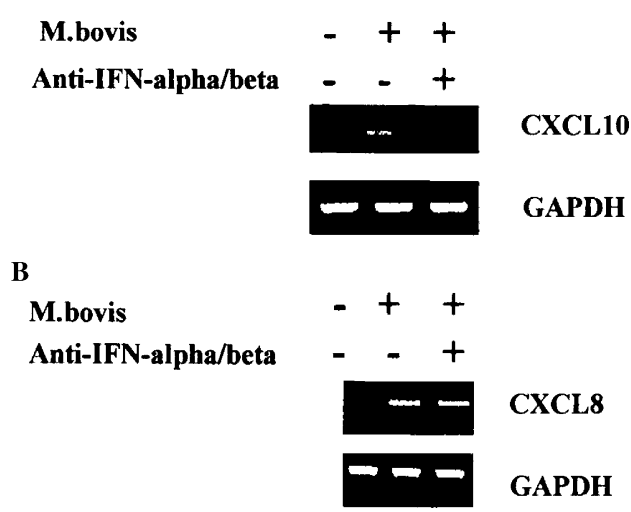

FIG. 5. IFN- $\alpha \beta$ mediates induction of CXCL10 gene expression in $M$. bovis-infected human monocytes. Total cellular RNA was isolated from $M$. bovis-infected human monocytes, treated with $10 \mu \mathrm{g} / \mathrm{ml}$ of a neutralizing anti-IFN- $\alpha \beta$ antibody for $24 \mathrm{~h}$, and the levels of (A) CXCL10 mRNA or (B) CXCL8 mRNA were measured by a semi-quantitative RT-PCR method. Controls were treated either with medium or with $M$. bovis alone. GAPDH served as an internal control. This is a representative RT-PCR experiment, which was repeated an additional three times with RNA extracted from different cell cultures.

levels of CXCL10 mRNA or CXCL8 mRNA were measured by the RT-PCR method. Controls were treated either with medium or with $M$. bovis alone. As shown in Fig. 5A,B, control cells treated with medium expressed undetectable constitutive levels of CXCL10 or CXCL8 mRNA, whereas $M$. bovis induced significant CXCL10 or CXCL8 mRNA expression in human monocytes. It is important to note that neutralization of type I IFN reduced CXCL10 mRNA expression at 24 $\mathrm{h}$ after $M$. bovis infection (Fig. 5A). In contrast, no a major change in the mRNA levels in $M$. bovis-induced CXCL8 was detected (Fig. 5B). These results are compatible with the aforementioned results obtained by ELISA.

\section{Discussion}

There is growing evidence that chemokines play an important role in the organization of the immune system. $^{22,23}$ CXCL10 is a recently identified chemokine that attracts Th1-activated and Tc-activated lymphocytes and natural killer cells in $M$. tuberculosis infection. ${ }^{24}$ We have demonstrated here for the first time that, following interaction with $M$. bovis, the human monocytes produced significant amounts of CXCL10. Importantly, we demonstrated that $M$. bovisinduced CXCL10 secretion is upregulated by the addition of exogenous type I IFN. This finding was observed in freshly isolated monocytes, and THP-1 monocytes and THP-1 macrophages, since both cell types are exposed to mycobacterial infection in vivo. Our data are in agreement with a recent study demonstrating that type I IFN may induce the expression of certain chemokine genes, ${ }^{25}$ and at the same time are consistent with a previous report demonstrating that the ability to respond to the IFN$\alpha \beta$ system is required for normal host defense. ${ }^{26}$ Furthermore, our data indicate that neutralization of endogenous type I IFN, using a neutralizing anti-IFN$\alpha \beta$ antibody, reduced the mRNA steady-state level of M. bovis-induced CXCL10 expression. It is possible that secretion of CXCL10 in our system could be ascribed to the activation of the nuclear factorkappaB (NF-кB) pathway. In fact, an early study has documented that NF- $\kappa \mathrm{B}$ may contribute to the activation of CXCL-8 chemokine genes in M. bovisinfected human monocytes. ${ }^{27}$ Therefore, our observations do not exclude the possibility that the secretion of CXCL10 is regulated in M. bovis-infected human monocytes, at least, in two ways: first, by the direct interaction between $M$. bovis and human monocytes leading to the activation of the NF- $\kappa \mathrm{B}$ complex; and, second, by the effect of type I IFN. We are currently investigating this possibility.

An early study documented a role for interleukin (IL)-12 in chemokine gene expression. ${ }^{28}$ Therefore, our results do not allow us to exclude the possibility of a feedback loop, where CXCL10 secretion precedes IL-12 and the subsequent increased levels of CXCL10 gene expression are dependent upon both IL-12 and IFN. However, it has been demonstrated that chemokines do not upregulate IL-12, and in fact downregulate its secretion. ${ }^{29-31}$

There is conflicting evidence on the role of IFN- $\alpha \beta$ during mycobacterial infection. On one hand, it has been shown that the administration of aerosolized IFN- $\alpha$ to patients receiving antimicrobial treatment for pulmonary tuberculosis lead to a more rapid decrease in the number of bacilli identified in sputum and earlier resolution of fever and some radiographic abnormalities. $^{32-34}$ Moreover, Cooper et al. ${ }^{35}$ recently showed a statistically significant increase in mycobacterial burden during the first 40 days postinfection in the lungs of mice having a null mutation in the IFN- $\alpha / \beta$ receptor, suggesting that type I IFN can play a defensive role during $M$. tuberculosis infection. Conversely, it has been demonstrated that, in mice, the induction of type I IFN by $M$. tuberculosis infection may be pathogenic, since the intranasal administration of IFN- $\alpha \beta$ to infected mice increases the bacterial burden and decreases the median survival time compared with infection alone. $^{36}$ However, it is well known that rapidly proliferating mycobacteria are more sensitive to antimicrobials. Therefore, enhanced mycobacterial replication induced by IFN- $\alpha$ could lead to the earlier response seen in patients with tuberculosis treated with type I IFN. As judged by the effects of IFN- $\alpha$ on $M$. bovis-induced CXCL10 expression, the data presented here suggest another pathway through which the type I IFN system can play a defensive role in 
mycobacteria infection. The extent to which type I IFN regulates $M$. bovis-induced CXCL10 chemokine expression in vivo will require further study.

In conclusion, the present investigation demonstrates that in vitro CXCL10 is expressed in M. bovisinfected human monocytes and that type I IFN plays a crucial role in regulating this expression. Further investigation of the importance of $M$. bovis-induced CXCL10 secretion in the regulation of the immune response against $M$. tuberculosis has to be confirmed in vivo. However, the functional relationship between chemokines and cytokines will undoubtedly be crucial to the understanding of protective immune response against tuberculosis.

ACKNOWLEDGEMENTS. This work was supported by a grant from the Coordinación General de Posgrado e Investigación (research project 20030159). P.M.S. is a COFAA, EDI and SNI fellow.

\section{References}

1. Kochi A. The global tuberculosis situation and the new control strategy of the World Health Organization. Bull World Health Org 2001; 79: 7175.

2. Fine PE, Carneiro IA, Milstein JB, Clements CJ. Issues relating to the use of BCG in immunization programmes. A discussion document. In WHO Vaccines and Biologicals (publication number 99.03). Geneva: World Health Organization, 1999: 1-45.

3. Zlotnik A, Yoshie O. Chemokines: a new classification system and their role in immunity. Immunity $2000 ; 12: 121-127$.

4. Sadek MI, Sada E, Toosi Z, Schwander SK, Rich EA. Chemokines induced by infection of mononuclear phagocytes with mycobacteria and present in lung alveoli during active pulmonary tuberculosis. $\mathrm{Am} \mathrm{J}$ Respir Cell Mol Biol 1998; 19: 513-521.

5. Méndez-Samperio P, Palma J, Vazquez A. Signals involved in mycobacteria-induced CXCL8 production by human monocytes. I Interferon Cytokine Res 2002; 22: 189-197.

6. Méndez-Samperio P, Garcia E, Vázquez A, Palma J. Regulation of interleukin- 8 by interleukin-10 and transforming growth factor $\beta$ in human monocytes infected with Mycobacterium bovis. Clin Diagn Lab Immunol 2002; 9: 802-807.

7. Riedel DD, Kaufmann SH. Chemokine secretion by human polymorphonuclear granulocytes after stimulation with Mycobacterium tuberculosis and lipoarabinomannan. Infect Immun 1997; 65: 4620-4623.

8. Lin YG, Gong J, Zhang M, Xue W, Barnes PF. Production of monocyte chemoattractant protein 1 in tuberculosis patients. Infect Immun 1998; 66: $2319-2322$

9. Mohammed KA, Nasreen N, Ward MJ, Mubarak KK, Rodriguez-Panadero F, Antony VB. Mycobacterium-mediated chemokine expression in pleural mesothelial cells: role of $\mathrm{C}-\mathrm{C}$ chemokines in tuberculosis pleurisy. J Infect Dis 1998; 178: 1450-1456.

10. Flynn JL, Chan J. Immunology of tuberculosis. Annu Rev Immunol 2001; 19: 93-129.

11. Collins HL, Kaufmann SHE. The many faces of host responses to tuberculosis. Immunology 2001; 103: 1-9.

12. Moser B, Loetscher P. Lymphocyte traffik control by chemokines. Nat Immunol 2001; 2: 123-128.

13. Kawakami K, Qureshi MH, Zhang T, et al. Interferon-gamma (IFN- $\gamma$ )protection and synthesis of chemoattractants for mononuclear leukocytes caused by IL-12 in the lungs of mice infected with Cryptococcus neoformans. Clin Exp Immunol 1999; 117: 113-122.

14. Akbar AN, Lord M, Salmon M. IFN-alpha and IFN-beta: a link between immune memory and chronic inflammation. Immunol Today 2000; 21: $337-342$.
15. Biron CA. Interferons alpha and beta as immune regulators: a new look. Immunity 2001; 14: 661-664.

16. Luft T, Pang KC, Thomas E, et al. Type I IFNs enhance the terminal differentiation of dendritic cells. J Immunol 1998; 161: 1947-1953.

17. Bogdan $\mathrm{C}$. The function of type I interferons in antimicrobial immunity. Curr Opin Immunol 2000; 12: 419-424.

18. Giacomini E, Iona E, Ferroni L, et al. Infection of human macrophages and dendritic cells with Mycobacterium tuberculosis induces a differential cytokine gene expression that modulates $\mathrm{T}$ cell response. J Immunol 2001; 166: 7033-7041.

19. Weiden M, Tanaka N, Qiao Y, et al. Differentiation of monocytes to macrophages switches the mycobacterium tuberculosis effect on HIV-1 replication from stimulation to inhibition: modulation of interferon response and CCAAT/enhancer binding protein beta expression. J Immunol 2000; 165: 2028-2039.

20. Chomczynski P, Sacchi N. Single-step method of RNA isolation by acid guanidinium thiocyanate-phenol-chloroform extraction. Anal Biochem 1987; 162: 156-159.

21. Tsuchiya S, Kobayashi Y, Goto Y, et al. Induction of maduration in cultured human monocytic leukemia cells by a phorbol diester. Cancer Res 1982; 42: $1530-1536$.

22. Yoshie $\mathrm{O}$, Imai $\mathrm{T}$, Nomiyama $\mathrm{H}$. Chemokines in immunity. $A d v$ Immunol 2001; 78: 57-110.

23. Baggioloni M, Dewald B, Moser B. Human chemokines: an update. Annu Rev Immunol 1997; 15: 675-705.

24. Orme IM, Cooper AM. Cytokine/chemokine cascades in immunity to tuberculosis. Immunol Today 1999; 20: 307-312.

25. Matikainen S, Pirhonen J, Miettinen M, et al. Influenza A and Sendai viruses induce differential chemokine gene expression. Virology 2000; 276: $138-147$.

26. Goodbourn S, Didcock L, Randall RE. Interferons: cell signalling, immune modulation, antiviral response and virus countermeasures. $J$ Gen Virol 2000; 81: 2341-2364.

27. Méndez-Samperio P, Palma J, Vazquez A. Roles of intracellular calcium and NF- $\mathrm{BB}$ in the bacillus Calmette-Guérin-induced secretion of interleukin-8 from human monocytes. Cell Immunol 2001; 211: $113-$ 122.

28. Sgadari C, Angiolillo AL, Tosato G. Inhibition of angiogenesis by interleukin-12 is mediated by the interferon-inducible protein 10. Blood 1996; 87: 3877-3882

29. Braun MC, Lahey E, Kelsall BL. Selective suppression of IL-12 production by chemoattractants. J Immunol 2000; 164: 3009-3017.

30. He J, Gurunathan S, Iwasaki A, Ash-Shaheed B, Kelsall BL. Primary role for Gi protein signaling in the regulation of interleukin 12 production and the induction of T helper cell type 1 responses. J Exp Med 2000; 191: $1605-1610$.

31. Karpus WJ, Kennedy KJ, Kunkel SL, Lukacs NW. Monocyte chemotactic protein 1 regulates oral tolerance induction by inhibition of $\mathrm{T}$ helper cell 1-related cytokines. J Exp Med 1998; 187: 733-741.

32. Giosue S, Casarini M, Alemanno L, et al. Effects of aerosolized interferon- $\alpha$ in patients with pulmonary tuberculosis. Am J Respir Crit Care Med 1998; 158: 1156-1162.

33. Palmero D, Eiguchi K, Rendo P, Castro Zorrilla L, Abate E, Gonzalez Montaner LJ. Phase II trail of recombinant interferon- $\alpha 2 b$ in patients with advanced intractable multidrug-resistant pulmonary tuberculosis: longterm follow-up. Int J Tuberc Lung Dis 1999; 3: 214-218.

34. Giosue S, Casarini M, Ameglio F, Zanglilli P, Palla M, Altieri AM, Bisetti A. Aerolized interferon-alpha treatment in patients with multi-drug-resistant pulmonary tuberculosis. Eur Cytokine Network 2000; 11: 99-103.

35. Cooper AM, Pearl JE, Brooks JV, Ehlers S, Orme IM. Expression of the nitric oxide synthase 2 gene is not essential for early control of Mycobacterium tuberculosis in the murine lung. Infect Immun 2000; 68: $6879-6882$.

36. Manca C, Tsenova L, Bergtold A, et al. Virulence of a Mycobacterium tuberculosis clinical isolate in mice is determined by failure to induce Th1 type immunity and is associated with induction of IFN- $\alpha / \beta$. Proc Natl Acad Sci USA 2001; 98: 5752-5757.

\section{Received 25 August 2004}

Accepted 10 September 2004 


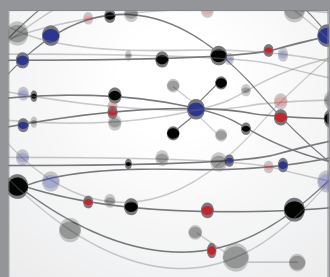

The Scientific World Journal
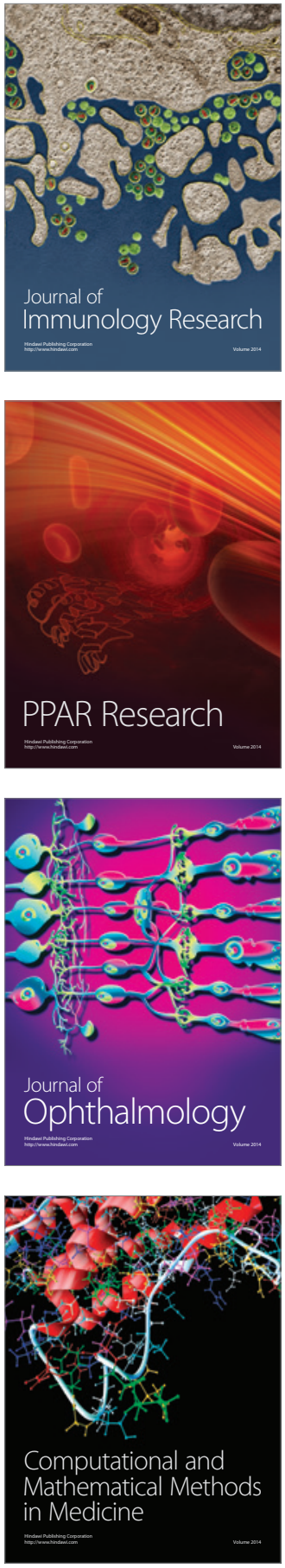

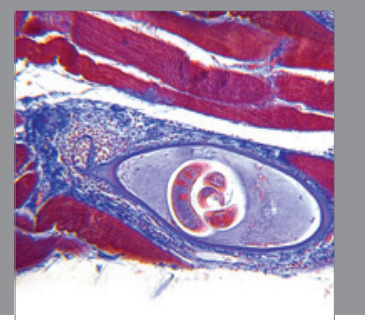

Gastroenterology

Research and Practice
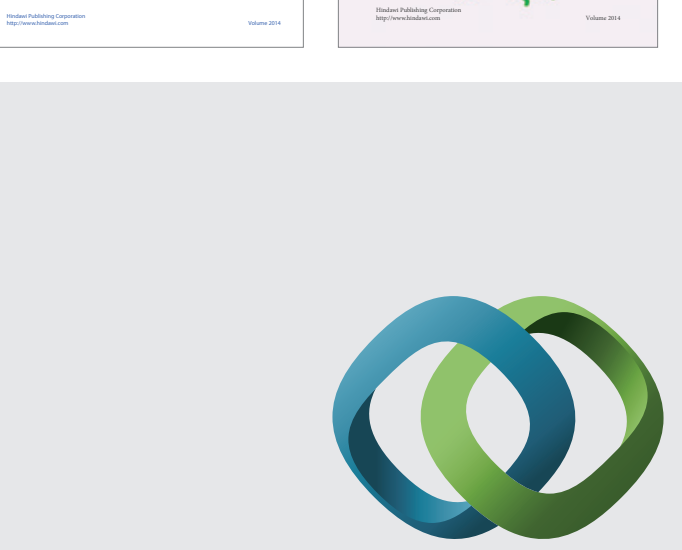

\section{Hindawi}

Submit your manuscripts at

http://www.hindawi.com
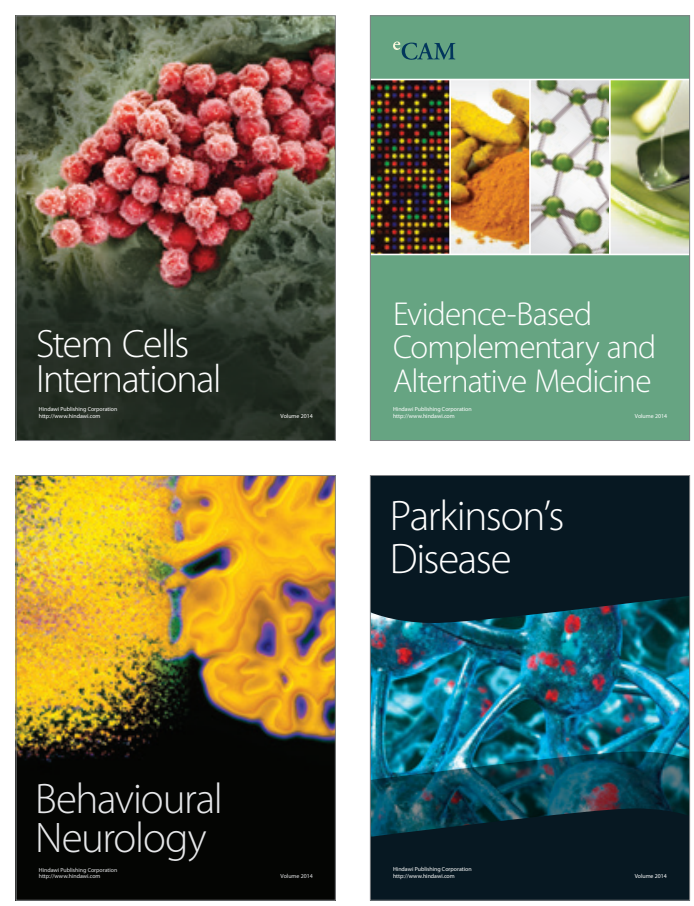

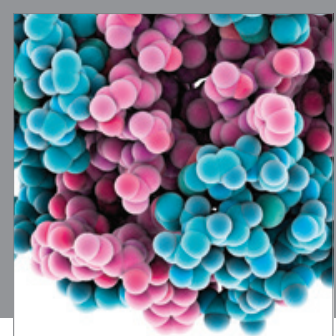

Journal of
Diabetes Research

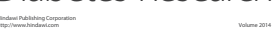

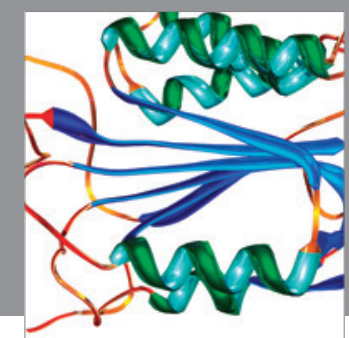

Disease Markers
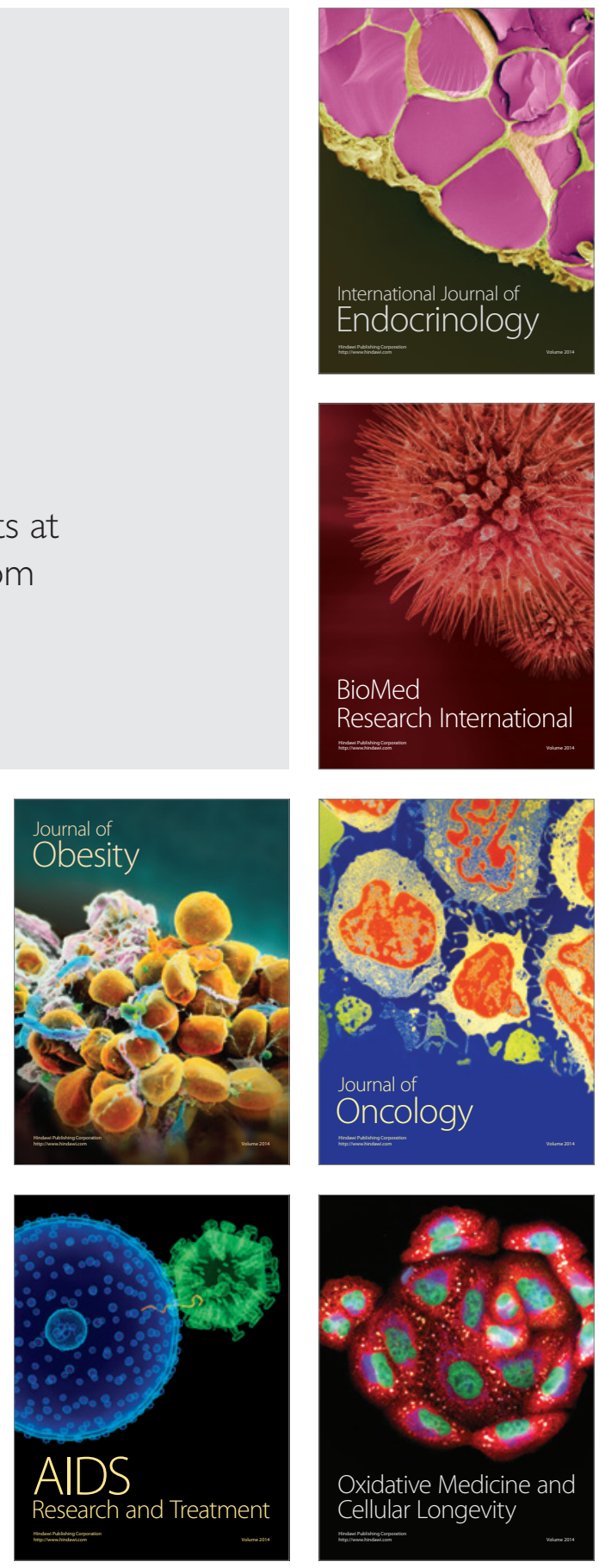